\title{
DAS RELAÇÕES ENTRE OS CONDICIONANTES MACROECONÔMICOS E A CONJUNTURA POLÍTICA: TRADE-OFFS DO ESTADO RENTISTA E DA ECONOMIA DA DEFESA NA ARÁBIA SAUDITA
}

\author{
ON THE RELATIONS BETWEEN MACROECONOMIC CONDITIONS AND THE \\ POLICY SETTING: TRADE-OFFS OF THE RENTISTIC STATE AND THE \\ DEFENSE ECONOMY IN SAUDI ARABIA
}

DOI: http://dx.doi.org/10.5380/cg.v9i1.70128

André Nunes ${ }^{1}$

Fernanda Delgado

Sabrina Evangelista Medeiros3

\begin{abstract}
Resumo
O objetivo deste artigo é analisar características do modelo econômico e geoestratégico do Reino da Arábia Saudita a partir do posicionamento do país diante do seu entorno regional no Oriente Médio, por condicionantes típicos de Estado Rentista e em matéria de economia da defesa. Por meio do estudo de caso e de metodologia exploratório-descritiva, observou-se o modelo econômico em curso que sustenta a sua robustez estratégica. A fim de demonstrar isso, o artigo apresenta primeiramente de que forma o caso saudita é relevante em termos geoestratégicos para a região e, em seguida, sobre a égide de um modelo de Estado Rentista cujas receitas nacionais advém em grande parte da exportação de hidrocarbonetos. Em seguida, apresenta-se a caracterização do sistema de compras militares do Reino, as suas capacidades e o seu modelo de Forças Armadas e investimento em sua indústria de defesa, incluindo a aquisição de plataformas e armamentos produzidos no exterior. A partir desse levantamento, pretende-se contribuir com os estudos sobre os modelos econômicos em matéria de defesa e suas eventuais repercussões para a política internacional, lançando luz o sobre um ator central para o Oriente Médio e para a estabilidade internacional do regime de segurança energética.
\end{abstract}

Palavras-Chave: Arábia Saudita; Defesa; Petróleo; Forças Armadas.

\begin{abstract}
The objective of this article is to analyze the characteristics of the economic and geostrategic model of the Kingdom of Saudi Arabia, based on the country's positioning vis-à-vis its regional territory in the Middle East, due to typical conditions of the rented state and in terms of defense economics. Through the case study and the exploratory-descriptive methodology, the current economic model that supports its robust strategic strategy. In order to demonstrate this, the article presents changes in the case of the Saudi that is relevant in geostrategic terms for a region, and then, on a rentier state model that receives revenue in large part from

\footnotetext{
1 Doutorando do Programa de Pós-Graduação em Ciências Militares (PPGCM-ECEME). E-mail: andrenuneso3@hotmail.com. ORCID: https://orcid.org/oooo-0003-0982-7680.

2 Professora e Assessora Estratégica na FGV Energia, E-mail: fernanda.delgado2@fgv.br. ORCID: https://orcid.org/oooo-0003-1177-5664.

3 Professora Associada de Relações Internacionais da Escola de Guerra Naval, Programa de Pós-Graduação em Estudos Marítimos. Doutora em Ciência Política pelo IUPERJ/IESP (2005), com bolsa no WZB, Berlin (DAAD). E-mail: sabrinamedeiros@yahoo.com. ORCID: https://orcid.org/oooo-0oo3-4954-3623.
} 
hydrocarbons. Then, the characterization of the Kingdom's military procurement system is presented, such as its sales and its model of Armed Forces and investment in its defense industry, including the acquisition of platforms and armaments used abroad.

Keywords: Saudi Arabia; Defense; Strategic Surrounding; Armed Forces.

\section{INTRODUÇÃO}

O Reino da Arábia Saudita é o segundo maior país do mundo árabe em extensão territorial, superado apenas pela Argélia. Reconhecido internacionalmente pelo protagonismo no mercado global de hidrocarbonetos naturais (encontrados no interior da terra a grandes pressões, acumulados geologicamente na forma de petróleo, gás natural, carvão, etc.), a Arábia Saudita é uma liderança política regional nos mundos árabe e islâmico, especialmente o de vertente sunita, além de ser uma importante potência militar no Oriente Médio. O fato de as duas principais cidades sagradas do Islã, Meca e Medina, encontrarem-se sob a soberania de Riad, proporciona aos sauditas um importante papel, principalmente no período do hajj, quando muçulmanos de todo o mundo peregrinam para Meca, ritual que deve ser atendido pelo menos uma vez na vida pelos fiéis do islã (SOURDEL, SOURDEL, 1996, p. 661-665). Não à toa, desde o reinado do rei Fahd al-Saud (1982-2005), os monarcas sauditas recebem o título de Guardião das Duas Mesquitas Sagradas, que faz referência à Grande Mesquita em Meca e à Mesquita do Profeta em Medina (AL-RASHEED, 2010, p. 144).

De acordo com informações disponibilizadas pela British Petroleum (2019), com dados referentes ao ano anterior, no Oriente Médio encontram-se cerca de 48,36\% e 38,4 \% das reservas mundiais de óleo e gás, respectivamente. Em 2018, os países locais produziram em média cerca de 31,7 milhões de barris por dia (mbpd) de petróleo, pouco mais de um terço da produção diária global, e 683,7 bilhões de metros cúbicos de gás natural por dia (m3/d), o equivalente a quase um quinto do total produzido no mundo. Ainda conforme os dados da BP, no setor petrolífero a Arábia Saudita desempenha papel de relevância global, sendo responsável por 17,2\% das reservas mundiais comprovadas - atrás apenas da Venezuela com 17,5\% - e por um terço das reservas do Oriente Médio. Os sauditas detêm a segunda maior produção do mundo com uma parcela de participação de 13\% no mercado internacional em 2018 (os EUA são os maiores produtores mundiais com uma fatia de 16,2\%). Além disso, foram os maiores exportadores de óleo cru do globo com uma média 367,4 milhões de toneladas comercializadas no mesmo ano. No setor de gás natural, apesar de ser um produtor em potencial com uma fatia de $3 \%$ das reservas internacionais e 2,9\% da produção mundial, o país não é um major player como outros atores regionais (Irã e o Catar).

Além das questões relacionadas ao óleo e gás, há os interesses sauditas envolvendo o Conselho de Cooperação do Golfo (CCG), um bloco regional formado por Arábia Saudita, Bahrein, Catar, Emirados Árabes Unidos (EAU), Kuwait e Omã, que tem como objetivos a cooperação nos campos cultural, científico, comercial e alfandegário, conforme sua Carta (1981). O CCG possui um 
braço armado conhecido como Força do Escudo da Península, que estabelece em seu artigo 2 que qualquer ataque ou ameaça a um dos membros é um ataque ou ameaça a todos os outros (QATAR, 2002). O Escudo já foi ativado em situações como a Guerra do Golfo de 1990-91, quando o Iraque invadiu o Kuwait; na guerra do Iraque em 2003 (também para a defesa do Kuwait), mas sem participação direta no conflito; e na revolta do Bahrein em 2011, para combater a onda de protestos populares no início da Primavera Árabe (AL-JABRI, 2017, p. 3-4).

A grande maioria dos países da península árabe faz parte de organizações internacionais (OIs) para integração cultural e religiosa e cooperação econômica nas quais os sauditas possuem grande influência. Dois exemplos de OIs com essas características são a Liga Árabe e a OCI (Organização para a Cooperação Islâmica), cuja sede se encontra na cidade de Jeddah, na Arábia Saudita, que também engloba o Irã, a Turquia e países de fora da região, como a Guiana e o Suriname. A parte oriental do Norte da África é de igual modo importante para os interesses econômicos de Riad. Até 2008, o governo saudita se contentava em importar alimentos do exterior para consumo de sua população, haja vista que o bioma desértico não é favorável para a atividade agrícola. Todavia, a partir de 2009, o Reino passou a investir na aquisição de fazendas no Sudão e na Etiópia para garantir a segurança alimentar do país e diminuir sua dependência de importação de alimentos de regiões longínquas (KLARE, 2012, p. 160, 161).

No contexto regional, a Arábia Saudita encontra-se envolvida de forma direta ou indireta em conflitos como as guerras civis da Síria e do Iêmen e no combate ao terrorismo. Somado a isto, a Arábia Saudita tem acompanhado um crescente nível da influência iraniana em seu entorno estratégico, o que tem levado o país a se aproximar veladamente de Israel e contribuído para a manutenção de um alto investimento militar (de 7 a 13\% do Produto Interno Bruto - PIB) desde o início do século XXI. Recentemente, o documento de visão estratégica Saudi Vision 2030 aponta o interesse saudita de expandir a aplicação de recursos financeiros no setor de defesa para fomentar o desenvolvimento da indústria de defesa nacional de modo que até 2030 uma grande parte das necessidades militares do Reino sejam atendidas internamente.

O objetivo do artigo é destacar as relações entre o perfil saudita de Estado Rentista dependente de exportações de petróleo e gás e as políticas de reaparelhamento e desenvolvimento da defesa nacional, considerando o ambiente de tensão em torno do suprimento energético internacional, do que representa ao Ocidente e da integridade da região. A hipótese é de que o modelo de Estado Rentista na Arábia Saudita soma-se ao modelo da defesa como mecanismo de ampliação da autonomia do país (1), razão pela qual tal questão ganhou atenção recente no planejamento estratégico nacional, mas isso pode gerar maior vulnerabilidade ao modelo (2). A metodologia é de caráter exploratório-descritivo, de modo que reunimos evidências sobre o estado da arte da economia de defesa e do seu modelo energético por meio de uma análise qualitativa. Utiliza-se, pois, estudo de caso para os fins desejados, ou seja, aqueles atrelados ao que o caso evidencia das relações entre economia da defesa e segurança energética. O estudo do caso levando- 
se em conta os aspectos das relações entre a economia e a defesa na Arábia Saudita se justifica porque um conflito direto de grande intensidade envolvendo o território do país pode causar crises políticas e econômicas com repercussão que ultrapassem as fronteiras nacionais, tendo a segurança energética internacional como mola propulsora de interesses exógenos relevantes.

Desse modo, o presente estudo encontra-se estruturado a partir do referencial teórico trazido para qualificar o estudo de caso da Arábia Saudita, pelo qual são tratados alguns aspectos referentes ao entorno estratégico da Arábia Saudita e a relevância do país diante das características da região. Em seguida, com ênfase na teoria dos Estados Rentistas e com apresentação de algumas percepções sobre a economia em matéria de defesa e sua aplicabilidade para o caso estudado manifestada, observa-se os gastos militares do Estado Saudita. Por último, destacada a configuração militar sauditas e com base em alguns resultados recentes do investimento do país em sua indústria de defesa, postulamos a transição de um modelo rentista para um modelo em busca de autonomia.

\section{O ENTORNO ESTRATÉGICO E OS CONDICIONANTES EXTERNOS DA DEFESA SAUDITA}

Embora o valor de comercialização do petróleo seja importante para o direcionamento de parte expressiva do PIB da Arábia Saudita para a área de defesa, este não é o único condicionante do investimento no setor. De acordo com Albalate, Bel e Elias (2012, p. 279), a análise das despesas militares de um país deve levar em consideração muitos fatores como, por exemplo, as ameaças de outros Estados, rebeliões internas, participação em sistemas de alianças, as características do regime político (no caso saudita uma monarquia hereditária), entre outros. Dentre estes, os autores apontam que a percepção de segurança, ou insegurança, em âmbito regional, são os principais determinantes dos gastos em defesa:

A segurança é a variável explicativa mais influente que determina os gastos militares e que a maioria das ameaças à segurança são colocadas por países vizinhos. É por esse motivo que os formuladores de políticas nos países em desenvolvimento examinam os orçamentos militares dos países em sua região geográfica (ALBALATE, D. et al., 2012, p. 281.Tradução nossa)4.

Como visto, na afirmação dos autores chama atenção a menção às ameaças provenientes de países vizinhos, o que remete a análise do entorno estratégico saudita, sugerido na Figura 1. Em primeiro lugar, ao analisar os orçamentos militares dos países da região observa-se que a grande maioria dos países do Oriente Médio - com exceção do Irã e dos países africanos demarcados no

\footnotetext{
4 Texto original: "Security is the most influential explanatory variable determining military spending and that most threats to security are posed by bordering countries. It is for this reason that policymakers in developing countries scrutinize the military budgets of countries in their geographical region".
} 
entorno a exemplo do Egito - investem aproximadamente 5\% do PIB no setor de defesa. Desde a Segunda Guerra Mundial a região tem sido alvo de conflitos: quatro conflitos árabe-israelenses (1948, 1956, 1967, 1973); e três conflitos envolvendo o Iraque - vizinho da fronteira Norte - como a Guerra Irã-Iraque (1980-88) e as duas Guerras do Golfo (1990-91 e 2003-2011) - na primeira, tropas iraquianas chegaram a invadir o território saudita atacando a cidade de Khafji, próxima à fronteira com o Kuwait.

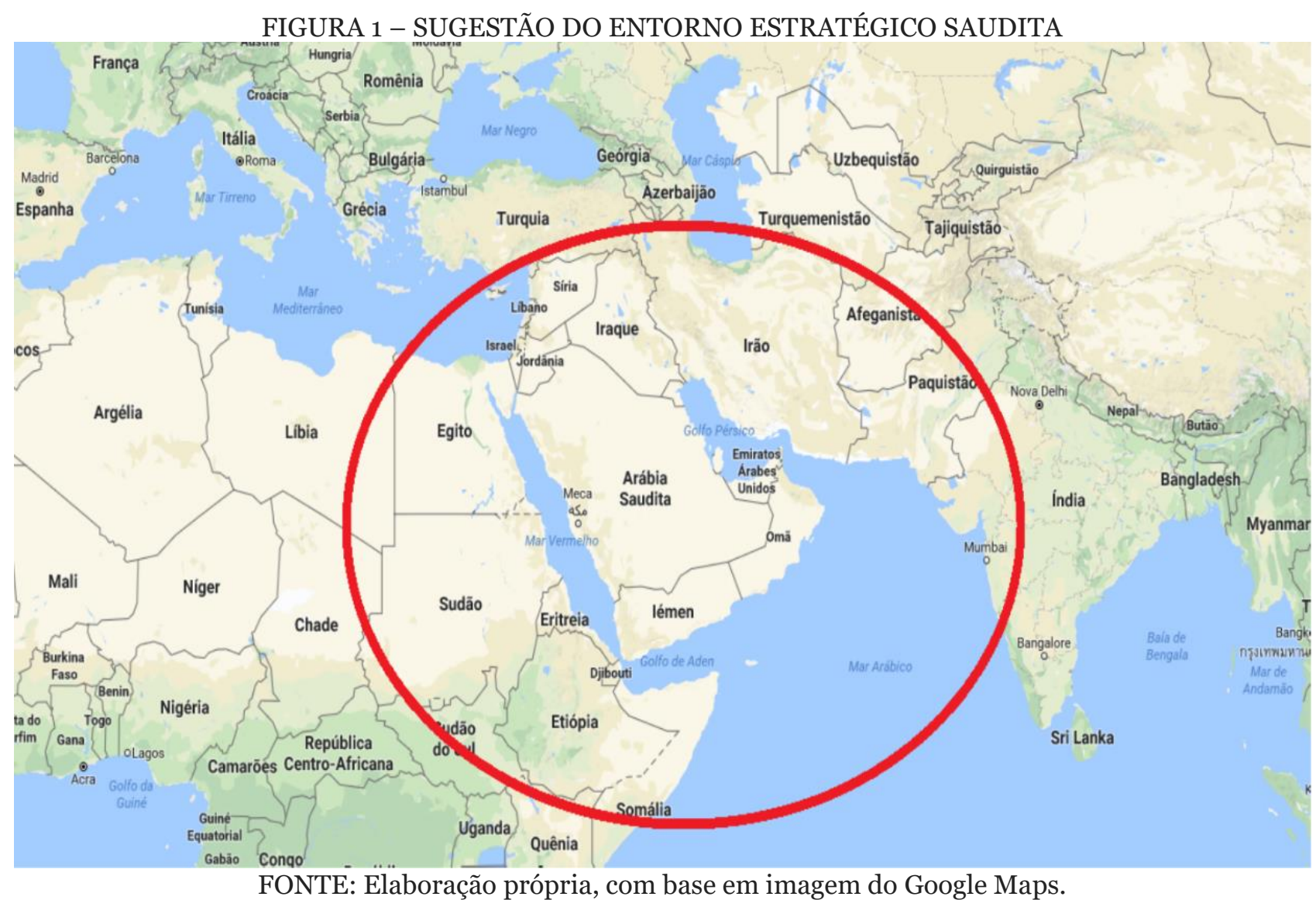

A rivalidade entre Riad e Teerã é também um fator que deve ser levado em consideração para entender as razões de um investimento tão alto em defesa. Um dos principais motivos da disputa entre os dois maiores países em extensão territorial do Golfo Pérsico se deu com a Revolução Iraniana de 1979, quando o Irã passou a ser uma república teocrática islâmica com base nos preceitos da vertente xiita da religião muçulmana. A tensão entre sunitas e xiitas é uma realidade, porém a rivalidade entre Riad e Teerã não pode ser reduzida de forma simplista ao sectarismo religioso quando existe uma disputa geopolítica entre os dois países nos campos econômico, estratégico, político e também militar na região do Golfo.

No início do século XXI, além dos conflitos entre Estados, os conflitos internos iniciados em decorrência da Primavera Árabe em 2011 podem ser entendidos como uma ameaça à estabilidade do regime monárquico da família Saud na Arábia Saudita. Estes conflitos geraram instabilidade em países como a Tunísia, Líbia, Egito, Síria e Bahrein. 
Atualmente a Arábia Saudita tem percebido o aumento da influência iraniana em pontos importantes do seu entorno, como por exemplo no Iraque pós Saddam Hussein; no Líbano, com apoio direto ao Hezbollah; no Iêmen; e também na Síria. Em 2011, ainda no período de maior pujança da Primavera Árabe, o Bahrein também foi palco de disputa “indireta” entre Riad e Teerã. Em junho de 2017, o Catar, que compartilha um dos maiores campos offshore de gás natural e petróleo com o Estado persa, foi isolado político e economicamente pela Arábia Saudita e por outros Estados árabes, dentre outros motivos, por uma declaração atribuída ao Emir Tamim bin Hamad alThani, e considerada inverídica por Doha, na qual ele teria afirmado não haver motivos para hostilidades árabes com o Irã (THE NATIONAL 2017).

Outro país com crescente influência política e militar no Golfo é a Turquia. Com um acordo de cooperação militar com o Catar desde 2015 e com uma base em Doha, Ancara aumentou o contingente de soldados na instalação já existente após a crise de 2017. Somado a isto, ambos os lados firmaram um novo acordo para a instalação de uma base naval no norte do país em março de 2018 (MIDDLE EAST MONITOR, 2018). No mês de outubro do mesmo ano, o Kuwait também anunciou um plano conjunto de defesa com os turcos.

Recentemente, tem sido observada uma aproximação velada entre a Arábia Saudita e Israel para conter a expansão da influência iraniana na região. Um dos impulsionadores deste acercamento foi o Acordo Nuclear Iraniano de 2015, criticado à época pelos dois países por entenderem que tal compromisso proporcionaria tempo para que Teerã desenvolva capacidade nuclear militar. Dessa forma, um possível Irã nuclearizado e com um programa avançado de mísseis balísticos é considerado como ameaça direta à sobrevivência de ambos.

Ainda no que diz respeito à Israel, a Arábia Saudita não reconhece e nem possui relações diplomáticas oficiais com o país desde sua fundação em 1948 com apoio dos EUA, o que, inclusive, motivou a primeira guerra árabe-israelense e estremeceu a incipiente relação diplomática entre sauditas e norte-americanos (RIEDEL, 2018, p. 24-26). A animosidade entre ambos se acentuou após a Guerra dos Seis Dias e a Conferência de Cartum de 1967, no Sudão, onde foram estabelecidos os "três nãos" à Israel5. Todavia, ambos os lados têm se aproximado de forma velada para conter a expansão da influência iraniana e turca em países na região e, mais precisamente, em países limítrofes de ambos, como Síria e o Líbano do lado israelense e Bahrein, Catar, Kuwait, Iraque e Iêmen do lado saudita.

Alguns dos sinais mais recentes da aproximação entre sauditas e israelense foram: uma reunião confidencial em maio de 2015 na embaixada norte-americana em Amã, Jordânia, quando representantes de Israel teriam oferecido o sistema de defesa antimísseis Iron Dome à Arábia Saudita, Kuwait e EAU (THE TIMES OF ISRAEL 2015); o primeiro voo direto de Riad a Tel-Aviv, em maio de 2017,em ocasião da primeira visita oficial do presidente Donald Trump ao Oriente Médio (TIBON; MELNITCKI, 2017); a ausência de um estadista na reunião de emergência da OCI de

5 Não à paz com Israel; não ao seu reconhecimento como Estado; e não às negociações comerciais. 
dezembro de 2017 em Istambul, após os EUA declararem o reconhecimento de Jerusalém como capital israelense, quando a grande maioria dos Estados participantes foram representados por seus principais líderes; a abertura do espaço aéreo saudita para voos da Índia para Israel em março de 2018 (CORNWELL; RABINOVITCH, 2018); e uma reunião, a princípio sigilosa, em uma capital do Golfo Pérsico envolvendo altos funcionários de inteligência de Israel, Arábia Saudita, Egito e EAU, cujo objetivo foi discutir maneiras de marginalizar a crescente influência do Irã e da Turquia no Oriente Médio (HEARST, 2019).

No entorno saudita também são encontrados três Estados com capacidade nuclear para fins militares. São eles: Israel, Paquistão e Índia. Israel é considerado como um dos principais inimigos em comum de muitos países árabes desde sua guerra de independência em 1948. O Paquistão, em seu turno, pratica exercícios conjuntos com as a Forças Armadas sauditas como, por exemplo, o exercício naval bienal Naseem al-Bahr que ocorre desde 1993. Já a Índia, que possui rivalidade militar com os paquistaneses ${ }^{6}$, é o maior mercado consumidor do petróleo saudita em seu entorno estratégico, sendo também uma potência nuclear.

Dentre os países nuclearizados de fora do Oriente Médio com presença militar na região destacam-se a Rússia, que possui uma base naval em Tartus, na Síria; a China e a França, com bases militares no Djibuti. Por outro ladom os EUA, principais fornecedores de armamentos para o Reino e o terceiro destino das exportações do petróleo produzido no país, também possuem uma base naval no Djibuti e outras três bases no Golfo, mais especificamente no Catar, Bahrein e Kuwait, sob o comando da Força Aérea e Marinha, nos dois primeiros e Exército e Fuzileiros no terceiro. Os britânicos também possuem bases permanentes no Golfo, localizadas no Bahrein e em Omã (MELVIN, 2019, p. 19; 20-21; 23-24).

O Djibuti também tem despertado o interesse saudita por sua importância estratégica, devido à sua posição geográfica, formando a margem ocidental do Estreito de Bab el-Mandeb em contraposição ao Iêmen a Leste. O pequeno Estado do Chifre da África em poucos anos será a sede da primeira base militar saudita fora do seu próprio território.

\section{ESTADOS RENTISTAS E ECONOMIA DE DEFESA: APLICAÇÃO PARA O CASO SAUDITA}

A definição de Estados Rentistas deriva da observação do comportamento de países quase exclusivamente dependentes da exportação de um único produto para gerar renda interna, de forma que o consumo de bens e serviços de sua população, assim como a cobrança de impostos de seus cidadãos, pouco alteram na composição da arrecadação financeira do seu modelo econômico (MAHDAVY. In: COOK, 2014, p. 428). Para a maioria dos chamados Estados Rentistas, essa renda

${ }^{6}$ Em especial por conta da disputa pela soberania do território da Caxemira. 
surge da extração de hidrocarbonetos (óleo e/ou gás) e sua comercialização no mercado internacional.

Um dos precursores deste tipo de análise foi o iraniano Hosseim Mahdavy que, ao analisar a indústria petrolífera iraniana nas décadas de 1950 e 1960, entendeu que o referido termo se aplicava aos países que recebiam regularmente montantes substanciais de renda externa advinda de indivíduos, empresas internacionais ou de governos de outros países. O autor ressalta que o montante recebido por um Estado Rentista não diz respeito somente ao petróleo vendido no mercado internacional, mas também se estende aos royalties cobrados pelos países produtores às empresas que exploram o recurso em territórios sob sua jurisdição; aos impostos cobrados por países de trânsito para a passagem de navios por canais aquaviários, como o Canal de Suez no Egito; e às tarifas pagas aos países que permitem a passagem de dutos através dos seus territórios nacionais (MAHDAVY. In: COOK, 2014, p. 428).

O egípcio Hazem Beblawi entende o papel de um Estado Rentista mais como uma função social do que uma categoria econômica. Para ele, esse Estado é percebido como membro de um grupo social que, apesar de não participar ativamente da produção econômica, recebe uma participação ou uma parcela do lucro do produto produzido por um outro agente - que seria o pagamento de royalties, no caso dos países produtores de petróleo dependentes do recurso. A característica distintiva do Estado Rentista residiria, portanto, na ausência de uma visão produtiva em seu comportamento e na dependência do interesse internacional por petróleo e do preço praticado no mercado externo (BEBLAWI, 1990, p. 86).

Após o Choque do Petróleo de 1973, muitos dos Estados-membros da Organização dos Países Exportadores de Petróleo (OPEP) - entre eles a Arábia Saudita - nacionalizaram as companhias estrangeiras que atuavam em seus territórios, tomando para si a função de extrair e vender o recurso no mercado internacional, o que significa que deixaram de receber o pagamento de arrendamento royalties para que o próprio Estado investisse na produção interna e, desse modo, guardasse o monopólio do processo decisório. Assim, os países da OPEP assumiram o controle sobre seus próprios recursos (YERGIN, 2010, p. 718).

Beblawi aponta quatro características de economias rentistas. São elas: (1) a inexistência de economia puramente rentista, mas sim de uma predominantemente rentista; (2) uma economia rentista depende da renda externa (para comprar seu petróleo) que, por sua vez, sustenta a economia sem um setor produtivo forte; (3) em um Estado Rentista poucos setores da economia estão envolvidos na geração da renda, enquanto a maioria encontra-se envolvida ou na distribuição ou na utilização dela; e (4) em um Estado Rentista o governo é o recipiente da renda externa que abastece a economia (BEBLAWI, 1990, p. 87,88).

Em abril de 2016, a Arábia Saudita publicou o documento de visão estratégica Saudi Vision 2030, pelo qual demonstra a intenção de orientar o país em uma direção contrária à dependência do petróleo no longo prazo. Todavia, a Arábia Saudita ainda pode ser enquadrada no conceito de Estado 
Rentista por ser um país que até então sobrevive da renda petrolífera e dele retira maior parte de suas receitas. De acordo com o Annual Statistical Bulletin 2019 da OPEP, estima-se que o setor de petróleo e gás em 2018 tenha representado cerca de 50\% do PIB e 70\% das receitas de exportação do país, o que torna o setor de hidrocarbonetos um dos pilares de sustentação da economia saudita, influenciando inclusive o direcionamento financeiro para sustentação de sua economia de defesa.

Dentro da teoria econômica dois fenômenos estão interligados e são muito característicos de Estados rentistas de óleo e gás: a maldição dos recursos naturais e a doença holandesa, ou Dutch disease (BRESSER-PEREIRA, 2008). Isso porque o fenômeno da doença holandesa é justamente comum entre os potenciais produtores de commodities e afetos à baixa industrialização justamente porque são dependentes de câmbio vantajoso às exportações de recursos naturais. Como contraponto ao Estado Rentista está o Estado desenvolvimentista, que tem na industrialização um fator de propulsão e crescimento, com base nas dimensões contextuais, institucionais e volitivas (PERISSINOTTO, 2014).

Importante destacar que a Arábia Saudita é o maior produtor de óleo cru da OPEP, e do mundo (atrás dos EUA), bem como o país com maior capacidade ociosa de produção, com um volume de aproximadamente $2 \mathrm{mbpd}$. No entanto, de acordo com dados do BP Statistical Review of World Energy 2019, é também o quinto maior consumidor mundial desse recurso com uma população de cerca de 34 milhões de pessoas, sendo superada apenas pelos EUA, China, Índia e Japão, todos com mais de 100 milhões de habitantes (China e Índia com mais de um bilhão). O bioma desértico, o calor, o baixo valor dos combustíveis e o investimento em usinas de dessalinização de água são algumas das razões para o enorme gasto energético do estado árabe.

Diante disso, a monarquia pede que a população mude seus hábitos de consumo e passe a depender menos do governo, o que abre espaço para que o setor privado participe mais ativamente da economia do país, atendendo assim requisitos do Saudi Vision 2030. A monarquia saudita segue um contrato social implícito composto de um generoso Estado de bem-estar social (welfare state), com altos salários para os cargos públicos. Como a dependência das exportações petrolífera continua a dominar a economia saudita, o orçamento do governo torna-se naturalmente vulnerável à volatilidade dos preços do petróleo e é essa situação que o governo busca contornar.

Em relação aos preços, nota-se que os países com menores populações e enormes reservas de petróleo são chamados de "pequenos absorvedores", o que os coloca em uma posição de estender a vida comercial de seus campos ao máximo e serem a favor de preços moderados: Arábia Saudita, Kuwait e dos Emirados Árabes Unidos (UAE). Já os países "grandes absorvedores", são os que têm grandes populações e menores reservas, o que os leva a ter necessidades financeiras sempre urgentes e a serem "falcões" em relação aos preços - Nigéria, Argélia e Indonésia. Outros países, como Irã e Iraque, estão em um grupo intermediário, com reservas e populações substanciais e que agem como “falcões” devido às suas necessidades financeiras. 
Segundo a Energy Information Administration (EIA), ligado ao Departamento de Energia dos EUA, os chamados chokepoints, ou pontos de estrangulamento mundiais para o trânsito marítimo de petróleo, são uma parte crítica da segurança energética global. Além disso, desde o início do século XXI, cerca de 80\% do comércio mundial, em volume, e mais de 70\% de seu valor é transportado por navios conforme apontam as publicações anuais do Review of Maritime Transport entre os anos de 2002 e 20197.

O estreito de Hormuz, no entorno saudita, e o Estreito de Malaca, localizado o Sudeste Asiático, por onde transita grande parte dos carregamentos do país árabe para seus parceiros da região, são os chokepoints estratégicos mais importantes do mundo em volume de trânsito de petróleo. O bloqueio de desses pontos, mesmo temporário, pode levar a aumentos substanciais nos custos totais de energia e nos preços mundiais. Os pontos de estrangulamento também deixam os petroleiros vulneráveis à pirataria e ataques terroristas. No entorno saudita, além de Hormuz, os estreitos de Bab el Mandeb e o canal de Suez, são os principais chokepoints.

A Arábia Saudita é um país que não possui acesso direto ao oceano aberto e, por isso, é bastante dependente, justamente, do trânsito marítimo por estreitos, seja para importação de produtos ou para escoar sua produção de hidrocarbonetos. Esse é um elemento geoestratégico que posiciona a Arábia Saudita de forma distinta de outros países produtores, somando-se ao determinante geopolítico do controle dos estreitos que também subordina a distribuição do petróleo e derivados, com grande efeito de chokekpoint por meio do estreito de Hormuz, por onde passam cerca de 19 mbpd (CUNNINGHAM, 2018).

A Tabela 1, que apresenta dados atualizados até o ano de 2016 do EIA, mostra a importância dos Estreitos para o mercado de hidrocarbonetos. Nela é possível verificar que aproximadamente um quinto da produção mundial passou por Hormuz e 4,8 milhões de bpd passam por Bab elMandeb, um volume correspondente a pouco menos da produção diária de Canadá e Irã e maior do que a brasileira e nigeriana. Dois Estados-chave nessa região são o Iêmen e o Djibuti, às margens do Estreito de Bab el-Mandeb, por onde trafegam navios petroleiros que chegam e saem do Golfo subindo e descendo o Mar Vermelho em direção à Europa e ao Leste Asiático. O Canal de Suez, controlado pelo Egito, é também uma via marítima importante para o escoamento da produção saudita para o Ocidente, assim como o $\mathrm{SUMED}^{8}$, um duto que atravessa o território egípcio ligando o porto de Ain Sokhna, no Mar Vermelho, à Alexandria no Mediterrâneo, sem necessidade de transportar petróleo por meio de navios através do Suez.

\footnotetext{
7 A versão de 2002 apresenta dados de 2001. O acesso a todas as edições mencionadas pode ser visualizada através do website do United Nations Conference on Trade and Development (UNCTAD) no seguinte link: https://unctad.org/en/pages/publications/Review-of-Maritime-Transport-(Series).aspx

8 Empreendimento que tem como acionistas as companhias petrolíferas estatais de Arábia Saudita, Catar, EAU, Egito e Kuwait.
} 
TABELA 1 - VOLUME DE PETRÓLEO TRANSPORTADO ATRAVÉS DE ESTREITOS, 2011-2016 (milhões de barris de petróleo ao dia)

\begin{tabular}{|c|c|c|c|c|c|c|}
\hline Location & 2011 & 2012 & 2013 & 2014 & 2015 & 2016 \\
\hline Strait of Hormuz & 17.0 & 16.8 & 16.6 & 16.9 & 17.0 & 18.5 \\
\hline Strait of Malacca & 14.5 & 15.1 & 15.4 & 15.5 & 15.5 & 16.0 \\
\hline Suez Canal and SUMED Pipeline & 3.8 & 4.5 & 4.6 & 5.2 & 5.4 & 5.5 \\
\hline Bab el-Mandab & 3.3 & 3.6 & 3.8 & 4.3 & 4.7 & 4.8 \\
\hline Danish Straits & 3.0 & 3.3 & 3.1 & 3.0 & 3.2 & 3.2 \\
\hline Turkish Straits & 2.9 & 2.7 & 2.6 & 2.6 & 2.4 & 2.4 \\
\hline Panama Canal & 0.8 & 0.8 & 0.8 & 0.9 & 1.0 & 0.9 \\
\hline Cape of Good Hope & 4.7 & 5.4 & 5.1 & 4.9 & 5.1 & 5.8 \\
\hline World maritime oil trade & 55.5 & 56.4 & 56.5 & 56.4 & 58.9 & $\mathrm{n} / \mathrm{a}$ \\
\hline World total petroleum and other liquids supply & 88.8 & 90.8 & 91.3 & 93.8 & 96.7 & 97.2 \\
\hline
\end{tabular}

FONTE: The U.S. Energy Information Administration - EIA. World Oil Transit Chokepoints.

Nos anos 2017 e 2018, os gastos da Arábia Saudita no setor de defesa representaram o terceiro maior orçamento do mundo no setor. Em 2018, com um PIB em torno de 768.2 bilhões de dólares, o governo do país destinou cerca de 67.6 bilhões para o setor militar, um valor equivalente a 8,8\% do PIB e 3,7\% do total mundial. Atualmente o país aparece no Top 5 dos gastos militares mundiais, atrás apenas de EUA e China e logo à frente de Índia e França (TIAN et al. 2019, p. 2). Apesar disso, apenas Omã superou a Arábia Saudita em investimento na área por parcela do PIB, com um total de 12,1\% do total para o setor militar. A proporção em relação ao PIB é um dado relevante, mas não é o único, posto que períodos de queda no crescimento ou aumento no orçamento podem estar disfarçados por essa proporção, que não revela valores absolutos; mas, para o índice da Organização do Tratado do Atlântico Norte (OTAN), a casa média compreende o entorno dos 2\% como parâmetro-base (HARTLEY, SANDLER, 1995; VIÑAS, 1984; FAINI et al., 1984).

Desde o início do século XXI, o investimento saudita em Defesa - excetuando-se os anos 2002 e 2003 - foi crescente no período 2000-2015, só caindo em 2016. Um dos determinantes da queda do orçamento do país árabe no setor foi a desvalorização do barril do petróleo no cenário internacional. Enquanto em 2014 o barril chegou a ser comercializado acima dos 100 dólares, influenciando, inclusive, o maior orçamento nacional do século para o setor no ano de 2015, em 2016 a Arábia Saudita foi forçada a reduzir os gastos com defesa em aproximadamente 27\%. A evolução do orçamento militar da Arábia Saudita pode ser observada, abaixo, no Gráfico 1. 


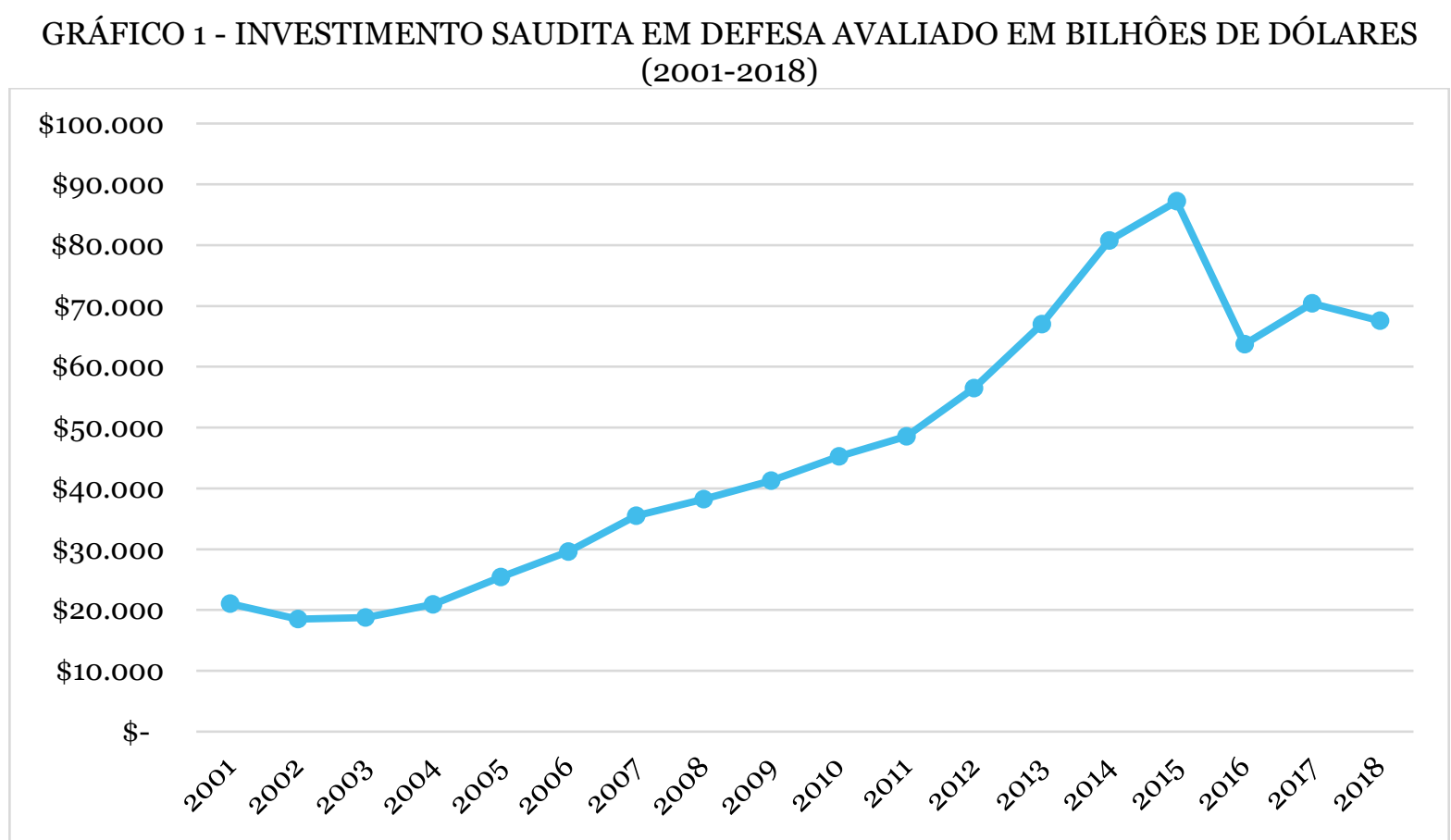

FONTE: Elaboração própria, com base nos dados do SIPRI Military Expenditure Database, 1949-2018.

Após o baixo orçamento para 2016, é possível sugerir que a recuperação nos investimentos em defesa em 2017 ocorreu especialmente devido ao acordo militar de 110 bilhões de dólares com os EUA anunciado em maio do mesmo ano. Ocasião, na qual, o presidente norte-americano Donald Trump visitou Riad em sua primeira viagem internacional na presidência dos EUA. O objetivo do acordo foi o aprimoramento das capacidades de defesa sauditas em diversos segmentos como, por exemplo, a defesa na área cibernética; das fronteiras, terrestre e marítima; do Reino contra potenciais inimigos estatais ou não; defesa do espaço aéreo com modernização e aquisição de meios; e, também, defesa antimísseis (US DEPARTMENT OF STATE, 2017).

\section{FORÇAS ARMADAS: MISSÃO E MATERIAL BÉLICO}

As Forças Armadas da Arábia Saudita, com um contingente de cerca de 227 mil militares na ativa, são constituídas pelo Exército; Marinha; Força Aérea; Força de Defesa Antiaérea; e Força de Mísseis Estratégicos. Todas eles são subordinados ao Ministério de Defesa e Aviação, que é o órgão incumbido de exercer a direção superior das Forças Armadas do Reino e que atualmente é dirigido pelo príncipe herdeiro Mohammed bin Salman.

O Exército, ou Força Real Terrestre, é a maior Força Armada saudita em termos de efetivo de pessoal, com aproximadamente 75 mil militares na ativa. Com o objetivo de defender o território nacional, o Exército saudita dispõe de 900 carros de batalha em suas fileiras de blindados, entre os 
quais: 140 unidades de blindados franceses AMX-30; 370 M1 Abrams, de fabricação norteamericana, nas versões A2/A2S e 390 M6o Patton, versão A3. A frota de carros de combate saudita é a quarta maior da região atrás do Egito (2.480 un.); Irã, com (1.513 un.); e Argélia (1.467 un.) (The Military Balance 2019).

Por outro lado, a aviação do Exército conta com aparelhos de asa rotativa produzidos, especialmente por empresas norte-americanas, como os 35 helicópteros de ataque Apache (11 da versão AH-64D e 24 de AH-64E), fabricados pela Boeing e os 46 helicópteros de assalto e transporte Black Hawk (22 da versão UH-6oA e 24 da UH-6oL), fabricados pela Sikorsky (comprada em 2015 pela Lockheed Martin). A defesa antiaérea do Exército fica em larga medida por conta míssil solo-ar FIM-92 Stinger, empregado para defesa de ponto (The Military Balance 2019).

O Brasil também se tornou um fornecedor de material bélico para o Exército saudita com a venda de 6 dezenas do sistema de foguetes de artilharia para saturação de área Astros II MK3, da Avibrás. A Arábia Saudita possui blindados leves importados do Canadá, da fabricante General Dynamics Land Systems Canada, além de outros veículos desse tipo produzidos por empresas nacionais como o al-Masmak - um veículo de transporte de pessoal blindado e resistente a minas produzido pela Saudi Groups. Além desses, o al-Fahd, projetado e construído na Arábia Saudita pela Abdallah Al Faris Company for Heavy Industries, possui capacidade anfíbia e é utilizado desde 1998 pela Guarda Nacional - que é uma força auxiliar da Força Terrestre nacional (NUNES, 2017).

A Marinha saudita, representada pela Força Real Naval Saudita, tem por atribuição principal garantir a segurança e os interesses marítimos do país, defendendo as áreas de costa e águas territoriais. Com um contingente de cerca de 13.500 militares, seu comando operacional é dividido em duas esquadras: uma no Golfo com sua base principal em al-Jubail e outra no Mar Vermelho sediada em Jeddah. A Força Naval saudita conta atualmente com 4 fragatas, 3 contratorpedeiros, 4 corvetas, 9 navios-patrulha e 3 navios-varredores para destruição de minas, além de outras embarcações de menor porte com tarefas múltiplas. Além disso, a Marinha saudita opera mísseis antinavio, AM39 Exocet, e antiaéreo AS-15TT, de fabricação francesa. A Força Real Naval Saudita também conta com um contingente extra de aproximadamente 3 mil fuzileiros.

Em novembro de 2017 o US Naval Institute informou o fechamento de um contrato de cerca de 6 bilhões de dólares entre a Marinha saudita e a empresa norte-americana Lockheed Martin para a construção de 4 fragatas para modernização dos meios de superfície da esquadra (LAGRONE, 2017). Em abril de 2018, um outro contrato de aproximadamente 2,5 bilhões de dólares foi firmado com a espanhola Navantia para a construção de 5 corvetas previstas para serem entregues em até cinco anos. O acordo foi fechado durante o período de visita oficial do príncipe Mohammed bin Salman ao país ibérico (NAVAL TODAY, 2018). Apesar de ser a maior Força Naval da Península Arábica, diferentemente de outros países do seu entorno como o Egito, Irã e Israel, a Marinha saudita não opera submarinos, embora já tenha demonstrado interesse em adquiri-los. 
A Real Força Aérea Saudita tem por atribuições proteger o espaço aéreo nacional; prestar apoio e abastecimento de suprimentos às tropas terrestres; realizar transporte de tropas quando solicitada; realizar operações de busca e salvamento na paz e na guerra; e também evacuar feridos por via aérea. Dentre os principais aparelhos operados pela Força, destacam-se 81 aeronaves F15 Eagle de fabricação norte-americana (algumas utilizadas para treinamento de pilotos), 67 unidades do europeu Panavia Tornado, desenvolvido em conjunto por Alemanha, Itália e Reino Unido, e 71 caças-bombardeiros Eurofighter Typhoon, também desenvolvido em conjunto por empresas de países europeus (Alemanha, Itália e Espanha).

A Força Aérea saudita também dispõe de aviões para transporte de tropas e material, como o norte-americano C-130 Hercules, uma aeronave muito utilizada por diferentes Forças Aéreas ao redor do mundo; e de aeronaves para abastecimento aéreo como o KC-13o Hercules, também fabricado nos EUA pela Lockheed Martin, assim como o A330 MRTT, da europeia Airbus. Outros meios de grande notabilidade são os aviões de controle e alerta aéreo antecipado operados pelo Reino, como o sueco Saab 2000 Erieye e norte-americano E-3A Sentry. A Força Aérea do país não dispões de helicópteros de ataque, somente para transporte de soldados. Os sauditas também já demonstraram interesse em adquirir o cargueiro KC-39o da Embraer para compor sua Força Aérea.

A missão da Força Real de Defesa Antiaérea, como bem diz seu nome, é fornecer proteção aérea para o Reino da Arábia Saudita utilizando de tecnologia moderna em sistemas de defesa aérea em conjunto com a Força Aérea. De acordo com afirmação disponível no website da instituição, para os sauditas as melhores Forças de Defesa Antiaérea se tonam fortes e eficazes quando reforçam o controle do ar, enfraquecendo oportunidades inimigas para atingir qualquer nível de superioridade aérea.

Para atender a sua missão, a Força dispõe de equipamentos tais como radares de busca tridimensional para controle do espaço aéreo, como o norte-americano Lockheed Martin AN/FPS117, e também opera sistemas de defesa antiaérea e antimísseis de longo alcance como o Raytheon MIM-104 Patriot, norte-americano. Em 2017, os sauditas mostraram interesse oficial em dois outros sistemas para compor as fileiras da Força: o norte-americano Terminal High Altitude Area Defense, mais conhecido como THAAD (US DEPARTMENT OF STATE, 2017); e o S-40o da Rússia, com quem Riad chegou a assinar memorando de entendimento (SAUDI CENTER FOR INTERNATIONAL COMMUNICATION, 2017) que esfriou após pressão dos EUA, dado que o S-40o é um sistema de contramedidas à aviação militar de países da OTAN e é, também, um sistema concorrente do THAAD. Além deles, como comentado anteriormente, o Iron Dome teria sido oferecido para a Arábia Saudita como plataforma de contramedidas aos ataques de mísseis disparados pelos rebeldes Houthis a partir do Iêmen.

Nesse sentido, a experiência de Riad em possuir uma Força em separado apenas para atender funções de característica defensiva para proteção do espaço aéreo se mostrava um caso de sucesso até o ataque às instalações de processamento de petróleo em 14 de setembro de 2014, feito por drones 
(provavelmente vindos do Iemen, parceiro do Irã). Ou seja, desde 1991 o preço do barril de petróleo não tinha tamanha alta e isso colocou a Arábia Saudita diante de outros desafios.

Há também a Força Real de Mísseis Estratégicos, cuja responsabilidade é o comissionamento e operação de mísseis estratégicos de médio e longo alcance. A Força de Mísseis foi criada com o objetivo de impulsionar as defesas do país por meio da dissuasão contra potencias inimigos. Nesse sentido, é possível conjeturar que sua tarefa seja a de dissuasão contra países como Israel e Irã, que também operam mísseis de médio e longo alcance no Levante e no Golfo. Essa suposição é corroborada pelas palavras do Rei Fahd, monarca à época da criação da instituição, que em 1988 alegou a operacionalidade da Força como o direito de exercer soberania em seu próprio território e de defender a nação e os lugares sagrados de todos os muçulmanos (CIGAR, 2014, p. 4,5, 8).

Atualmente a Força Real de Mísseis Estratégicos possui entre seus principais equipamentos, armamentos de origem, a exemplo dos mísseis balísticos Dong Feng (DF): o DF-21 de alcance intermediário (aproximadamente $1.700 \mathrm{~km}$ ); e o DF-3, também de alcance intermediário (até 4.000 $\mathrm{km}$ ), mas superior ao anterior em poder de destruição pela capacidade de carregar uma ogiva nuclear (LEWIS, 2014). Os primeiros mísseis foram entregues em 1987 após reuniões secretas entre sauditas e chineses intermediadas pelo Paquistão. Os EUA só tomaram conhecimento das aquisições sauditas em 1988, através de seu serviço secreto, e exigiram a retirada do armamento do país. Os árabes recusaram a exigência e se comprometeram a não instalar ogivas nucleares nos mísseis (RIEDEL, 2018, p. 93-94).

A maior parte dos armamentos sauditas são de fabricação estrangeira. Segundo dados do SIPRI Arms Transfers Database, no acumulado dos anos do século XXI, a Arábia Saudita figura como o terceiro país que mais importou material bélico convencional no mundo, atrás de China e Índia, e desde $2015^{9}$ o país árabe é o maior comprador de armamento estrangeiro, ultrapassando os indianos. Além disso, o país investe cerca de apenas 2\% desse capital em sua própria indústria bélica. Segundo o Saudi Vision 2030 (2016, p. 48), os sauditas pretendem reforçar os investimentos no setor militar em cerca de 50\% até o ano de 2030, o que se mostra um plano ambicioso para um país com um amplo histórico de aquisições de materiais produzidos no exterior e sem uma indústria forte. Apesar disso, o documento enfatiza que isto só será possível por meio de investimentos diretos e parcerias estratégicas com empresas, mesmo do exterior, que possam fornecer treinamento de pessoal, transferência de tecnologia e conhecimento para a fabricação e manutenção de armamentos. O documento revela, pois, o interesse em promover autonomia, mas o modelo constituído ainda não tem os componentes de transferência de tecnologia e autonomia como requerido, baseado em modelos possíveis e em uso como os de offset - acordos de compensação comercial, industrial e tecnológica (BRUSTOLIN et al, 2016).

Além da Abdallah al-Faris Company for Heavy Industries e da Saudi Groups, fabricantes dos blindados al-Fahd e al-Masmak, a indústria de defesa saudita também conta com outras empresas

9 Em 2016 a Índia ficou à frente da Arábia Saudita. 
com produção voltada para o setor militar, a exemplo da Military Industries Corporation, que produz armas leves, explosivos e munições, e a Advanced Eletronics Company, que investe no desenvolvimento de tecnologia em comunicação, aviônica e guerra eletrônica. Em maio de 2017, a Arábia Saudita anunciou o lançamento da Saudi Arabian Military Industries (SAMI), uma companhia estatal ligada ao Fundo de Investimento Público da Arábia Saudita que atuará no fornecimento de serviços em quatro unidades de negócios: (1) sistemas de ar, que inclui a manutenção e o reparo de aeronaves de asa fixa e a fabricação e reparo de veículos aéreos não tripulados; (2) sistemas terrestres com fabricação e reparação de veículos militares; (3) armas e mísseis, incluindo munições; e (4) defesa eletrônica, que inclui radares, sensores e sistemas de comunicação.

As quatro áreas de investimento da SAMI mencionadas acima, além da prestação de serviços pontuais, visam também o investimento de capital financeiro em pesquisa e desenvolvimento no Reino, com o objetivo de atender demandas das Forças Armadas nacionais a partir da geração de empregos e de mão-de-obra capacitada internamente, como cientistas e engenheiros. Para alcançar este propósito, o website da SAMI aponta seis metas principais da empresa: assumir um papel de liderança no setor da indústria militar global até 2030; desenvolver a força de trabalho saudita para os mais altos padrões globais; aprimorar e localizar as capacidades das empresas do Reino e focar nas competências únicas e inerentes do país no setor de defesa; criar produtos e serviços de classe mundial que possam competir em qualidade e valor no mercado internacional; assegurar parcerias estratégicas de confiança e de longo prazo que possam garantir segurança no exterior e prosperidade nacional; e contribuir para internalizar mais de 50\% dos gastos militares até 2030 e assim promover a autossuficiência saudita no setor de defesa.

Em outubro de 2017, o governo saudita anunciou por meio do Saudi Center for International Communication o primeiro grande acordo internacional envolvendo a SAMI feito com a russa ROSOBORONEXPORT. Além da possível aquisição de armamentos como o S-400, o memorando entre as duas companhias prevê produção de rifles de assalto Kalashnikov AK -103 e munições em território saudita, além de transferência de tecnologia para a produção do míssil guiado antitanque Kornet-EM, do sistema lançador múltiplo de foguetes TOS-1A e do lançador automático de granadas AGS-30. Mais do que a importação de novos sistemas de armamentos, a agência de comunicações saudita reportou que o objetivo do contrato com a ROSOBORONEXPORT é garantir a transferência de tecnologia e localizar a manufatura desses sistemas de armamento no Reino a fim de cumprir com as metas para defesa estabelecidas pelo Saudi Vision 2030.

Outros importantes acordos foram alcançados pela SAMI com empresas europeias. Em janeiro de 2018 a estatal árabe anunciou a criação de duas joint ventures com a francesa Thales, para defesa antiaérea, instalação de radares e comunicação, entre outras áreas; e com a belga $C M I$ Defense, que inclui projetos voltados para a entrega de sistemas de torres de alta potência para veículos blindados, engenharia eletrônica, montagem de veículos e outros serviços. 
Para o setor naval a Arábia Saudita também tem buscado formalizar acordos internacionais com vistas a desenvolver meios capazes de suprir às exigências da Marinha local. No dia 6 de novembro de 2018 a SAMI e a Navantia firmaram contrato para o estabelecimento da SAMI Navantia Naval Industries, uma joint venture criada para conduzir a construção das 5 corvetas encomendadas em abril do mesmo ano da empresa espanhola. O foco desta recém-criada empresa recairá no desenvolvimento de sistemas de guerra eletrônica e na instalação e integração de sistemas de combate nas duas últimas embarcações, as quais serão finalizadas em estaleiros sauditas (SAUDI ARABIA, 2018). Em fevereiro de 2019 a estatal saudita e a francesa Naval Group também apresentaram um acordo inicial, por meio de um memorando de entendimento, para a criação de uma joint venture que contribuirá na localização de habilidades e capacidades industriais essenciais para a Arábia Saudita.

\section{CONSIDERAÇÕES FINAIS}

A Arábia Saudita tem procurado a colaboração de parceiros internacionais para fazer valer seus interesses. Como um dos regimes mais fechados no mundo, a dependência de importações de bens de defesa caracteriza o estado de vulnerabilidade que alcança um expressivo percentual do PIB em matéria de defesa, enquanto a tendência mundial foi de decréscimo.

A Arábia Saudita é um país que constantemente tem se envolvido em conflitos regionais, desde guerras entre Estados à intervenção militar em países vizinhos. Sempre entre os 10 maiores orçamentos militares do mundo no século XXI, o Reino tem por característica ser um grande importador de material bélico. No entanto, este é uma realidade que o Estado árabe pretende alterar, visando produzir grande parte dos produtos relacionados ao setor de defesa internamente estruturando um planejamento de médio e longo prazo para cumprir, ao menos em parte, os objetivos do Saudi Vision 2030 para esse setor.

Na hipótese apresentada, é a vulnerabilidade de Estado Rentista que provoca as assimetrias entre os projetos econômico e político com repercussões regionais e internacionais. Dessa forma, tomando como alicerce a teoria do Estado Rentista, a economia da defesa acaba por estar direcionada aos investimentos imediatos que pouco estão afetos ao desenvolvimento e mais afetos às circunstâncias da dependência das exportações de óleo, criando uma grande vulnerabilidade ao sistema dado o ambiente regional saudita. Ou seja, ainda que o país invista cerca de um décimo do PIB - em grande parte composto pelos lucros do petróleo - no setor de defesa, isso é insuficiente para um projeto de estabilidade política de longo-prazo, mesmo considerando-se que a Arábia Saudita tem na parceria estratégica com os EUA o seu grande alicerce.

Mesmo com apenas dois anos de existência, a SAMI tem caminhado a passos largos para o fortalecimento da indústria de defesa nacional já existente e para o desenvolvimento de novas áreas 
e sistemas que ainda não são dominadas pelos sauditas. Embora o objetivo de localizar 50\% das necessidades de defesa até 2030 ainda esteja longe de ser alcançado, é possível afirmar que com recursos financeiros e com planejamento, a Arábia Saudita terá condições de se tornar uma referência na área de defesa entre os países árabes.

Por outro lado, a sua condição atual de Estado Rentista revela a dependência e vulnerabilidade da Arábia Saudita na matéria, o que se soma à insegurança pelos estreitos para exportação de petróleo e aos conflitos internos em países do entorno, assim como entre eles. O recente agravamento das tensões, no segundo semestre de 2019, por ocasião do impedimento de passagem de navios cargueiros estrangeiros no estreito de Hormuz, ampliado pelo ataque às instalações de produção de petróleo em território da Arábia Saudita (elevando os preços do barril para valores não praticados depois de 1991), dão ainda maior significado ao recondicionamento do planejamento dos investimentos em defesa e, em especial, ao adestramento dos militares dos cinco ramos de suas Forças Armadas.

Assim, é possível concluir que diante das ameaças percebidas em seu contexto regional e da importância que representa para o mundo árabe e muçulmano, o Reino da Arábia Saudita manterá um alto investimento em defesa nos próximos anos. No entanto, para atender às demandas estratégicas do Saudi Vision 203o, é provável que o esforço de localizar parte dos investimentos no setor na indústria de defesa local esteja voltado a cobrir as vulnerabilidades presentes nas últimas crises envolvendo o país e seu entorno estratégico, o que no futuro poderá se traduzir em exportação de armamentos para países vizinhos e para outros parceiros do Reino.

* Artigo recebido em 09 de novembro de 2019, aprovado em 23 de março de 2020.

\section{REFERÊNCIAS}

ALBALATE, D.; BEL, G.; ELIAS, F. Institutional Determinants of Military Spending. Journal of Comparative Economics. Vol. 40. 2012, p. 279-290.

AL-JABRI, Maisa M. A. Gulf Security: Peninsula Shield Force. Security in the Gulf, International Security Conference, 2017. Disponível em: https://www.researchgate.net/publication/316666885_Gulf_Security_Peninsula_Shield_Force_a nd_Iran Acessado no dia 20 de março de 2020.

AL-RASHEED, Madawi. A History of Saudi Arabia. Cambridge: Cambridge University Press, 2010.

BEBLAWI, Hazem. The Rentier State in the Arab World. In: LUCIANI, Giacomo. The Arab State. Berkeley: University of California Press, 1990. 
BRESSER-PEREIRA, L. C. The Dutch disease and its neutralization: A Ricardian approach. Revista de Economia Política, 28:47-71 2008.

\section{BRITISH PETROLEUM (BP). British Petroleum Statistical Review of World Energy 2019. Disponível em: https://www.bp.com/content/dam/bp/business- sites/en/global/corporate/pdfs/energy-economics/statistical-review/bp-stats-review-2019-full- report.pdf Acessado no dia 30 de julho de 2019.}

BRUSTOLIN, Vitelio Marcos; DE OLIVEIRA, Cleber Almeida; SENNA, Claudio José D.'Alberto. Análise das Práticas de Offset nos Contratos de Defesa no Brasil. Revista da Escola de Guerra Naval, Rio de Janeiro, v. 22, n. 1, p. 169-196, 2016.

CARTA do Conselho de Cooperação do Golfo = GULF Cooperation Council Charter. 25 de maio de 1981. Disponível em: https://www.gcc-sg.org/en-us/AboutGCC/Pages/Primarylaw.aspx Acessado no dia 18 de março de 2020.

CIGAR, Norman. Saudi Arabia's Strategic Rocket Force: The Silent Service. Marine Corps University. Middle Eastern Studies Monographs No. 6, September 2014. Disponível em: https://fas.org/nuke/guide/saudi/srf.pdf Acessado no dia 13 de outubro de 2017.

CUNNINGHAM, Nick. The 4 Key Chokepoints For Oil, OilPrice.com, July 26, 2018. Disponível em: https://oilprice.com/Energy/Energy-General/The-4-Key-Chokepoints-For-Oil.html Acessado no dia 2 de novembro de 2019.

CORNWELL, Alexander; RABINOVITCH, Ari. Independent, March 23, 2018. Disponível em: https://www.independent.co.uk/news/world/middle-east/saudi-arabia-israel-airspace-riyadh-telaviv-flight-air-india-iran-flight-times-airlines-a8269891.html Acessado no dia 7 de maio de 2018.

FAINI, Riccardo; ANNEZ, Patricia; TAYLOR, Lance. Defense spending, economic structure, and growth: Evidence among countries and over time. Economic development and cultural change, v. 32, n. 3 , p. 487-498, 1984.

HARTLEY, Keith; SANDLER, Todd. Handbook of Defense Economics, Volume 1. Amsterdam: Elsevier Science, 1995.

HEARST, David. REVEALED: How Gulf states hatched plan with Israel to rehabilitate Assad. Middle East Eye, January 8, 2019. Disponível em: https://www.middleeasteye.net/news/revealed-how-gulf-states-hatched-plan-israel-rehabilitateassad Acessado no dia 6 de março de 2019.

KLARE, Michael T. The Race for What's Left: The Global Scramble for The World's Last Resources. New York: Metropolitan Books, 2012.

LAGRONE, Sam. Lockheed Martin Awarded First Contract for New Saudi Frigates. US Naval Institute, November 30, 2017. Disponível em: https://news.usni.org/2017/11/30/lockheedmartin-awarded-first-contract-new-saudi-frigates Acessado no dia 20 de fevereiro de 2018.

LEWIS, Jeffrey. Why Did Saudi Arabia Buy Chinese Missiles?. Foreign Policy, Jan. 2014. Disponível em: http://foreignpolicy.com/2014/o1/30/why-did-saudi-arabia-buy-chinese-missiles/ Acesso no dia 12 de outubro de 2017.

MAHDAVY, Hosseim. Patterns and Problems of Economic Development in Rentier States: the Case of Iran. In: COOK, M. A. Studies in the Economic History of the Middle East: from the rise of Islam to the present day. New York: Routledge, 2014. 
MELVIN, Neil. The Foreign Military Presence in the Horn of Africa Region. Stockholm International Peace Reserach Institute, April, 2019. Disponível em: https://sipri.org/sites/default/files/2019-04/sipribp1904.pdf Acesso em: 19 de maio de 2020.

QATAR signs Turkey naval military base agreement. Middle East Monitor, March 14, 2018. Disponível em: https://www.middleeastmonitor.com/20180314-qatar-signs-turkey-naval-militarybase-agreement/ Acessado dia 24 de abril de 2019.

NAVAL TODAY. Saudi Arabia: Spain finalize Avante 2200 corvette deal, April 13, 2018. Disponível em: https://navaltoday.com/2018/04/13/saudi-arabia-spain-finalize-avante-2200corvette-deal/ Acessado no dia 23 de abril de 2018.

NUNES, André. A Indústria de Defesa na Arábia Saudita. Jornal de Relações Internacionais, 22 de setembro de 2017. Disponível em: http://jornalri.com.br/artigos/industria-de-defesa-naarabia-saudita Acesso no dia 4 de outubro de 2017.

ORGANIZATION OF PETROLEUM EXPORTING COUNTRIES - OPEC. Annual Statistical Bulletin 2019. Disponível em: https://www.opec.org/opec_web/en/publications/202.htm Acessado no dia 3 de novembro de 2017.

PERISSINOTTO, Renato. O conceito de Estado Desenvolvimentista e sua utilidade para os casos brasileiro e argentino. Revista de sociología e política, v. 22, n. 52, p. 59-75, 2014.

QATAR. Al Meezan - Qatari Legal Portal. The Joint Defence Agreement of the Cooperation Council for the Arab States of the Gulf. Disponível em: http://www.almeezan.qa/AgreementsPage.aspx?id=1527\&language=en Acessado no dia 3 de maio de 2018.

RIEDEL, Bruce. Kings and Presidents: Saudi Arabia and the United States since FDR. Washington: Brookings Institution Press, 2018.

SAUDI ARABIA. Ministry of Defence and Aviation. Royal Saudi Air Defense Force. Disponível em: https://www.rsadf.gov.sa/Subs.aspx?PID=1 Acessado no dia 14 de outubro de 2017.

SAUDI ARABIA. Ministry of Defence and Aviation. Royal Saudi Strategic Missiles Force. Disponível em: https://www.rsadf.gov.sa/Subs.aspx?PID=1 Acessado no dia 7 de junho de 2018.

SAUDI ARABIA. Saudi Vision 203o. Disponível em: http://vision2030.gov.sa/en Acessado no dia 25 de maio de 2017.

SAUDI CENTER FOR INTERNATIONAL COMMUNICATION. Saudi Arabian Military Industries Signs Agreement and MOU With Russia's ROSOBORONEXPORT, Oct. 5, 2017. Disponível em: https://cic.org.sa/2017/10/saudi-arabian-military-industries-signsagreement-and-mou-with-russias-rosoboronexport/ Acessado no dia 16 de outubro de 2017.

SOURDEL, Janine; SOURDEL, Dominique. Dicitionnaire historique de l'islam. 1. ed. Paris: Presses Universitaires de France, 1996.

STOCKHOLM INTERNATIONAL PEACE RESEARCH INSTITUTE - SIPRI. Arms Transfers Database, 2001-2018. Disponível em: http://armstrade.sipri.org/armstrade/html/export_toplist.php Acessado no dia 6 de novembro de 2019.

STOCKHOLM INTERNATIONAL PEACE RESEARCH INSTITUTE - SIPRI. Military Expenditure Database, 1949-2018. Disponível em: https://www.sipri.org/databases/milex Acessado no dia 3 de maio de 2019. 
THE NATIONAL. Qatar claims emir's Iran comments had been faked, Riad, 25 de maio de 2017. Disponível em: http://www.thenational.ae/world/middle-east/qatar-claims-emirs-irancomments-had-been-faked Acessado no dia 12 de outubro de 2017.

THE TIMES OF ISRAEL. Saudi Arabia 'rejects Israeli offer to supply Iron Dome', May 23, 2015. Disponível em: https://www.timesofisrael.com/saudi-arabia-rejected-israeli-offer-of-irondome/ Acessado no dia 26 de janeiro de 2018.

\section{THE U.S. ENERGY INFORMATION ADMINISTRATION - EIA. World Oil Transit Chokepoints. Disponível em: https://www.eia.gov/beta/international/regions- topics.cfm?RegionTopicID=WOTC Acessado no dia 3 de outubro de 2017.}

TIAN, Nan. et al. Trends in World Military Expenditure, 2018. Stockholm International Peace Research Institute - SIPRI. April 2019.

TIBON, Amir; MELNITCKI, Gili. Trump's Trip to Israel Is the First Direct Flight from Saudi Arabia to the Jewish State. Haaretz, May 22, 2017. Disponível em: https://www.haaretz.com/israelnews/trump-s-trip-is-first-direct-flight-from-saudi-arabia-to-israel-1.5473549 Acessado no dia 7 de maio de 2018.

UNITED NATIONS CONFERENCE ON TRADE AND DEVELOPMENT. Review of Maritime Transport [2002-2019]. New York and Geneva, 2019. Disponível em: https://unctad.org/en/pages/publications/Review-of-Maritime-Transport-(Series).aspx Acesso em: 25 de junho de 2020 .

US DEPARTMENT OF STATE. Supporting Saudi Arabia's Defense Needs. Office of the Spokesperson. Washington D.C., 20 de maio de 2017. Disponível em: https://www.state.gov/r/pa/prs/ps/2017/05/270999.htm Acessado em 16 de outubro de 2017.

VIÑAS, Angel. Economía de la Defensa y Defensa Económica: Una Propuesta Reconceptualizadora. In: Revista de Estudios Políticos. No. 37, 1984, p. 25-48.

YERGIN, Daniel. O Petróleo: Uma história mundial de conquistas, poder e dinheiro. São Paulo: Paz e Terra, 2010.

YIN, Robert K. Estudo de Caso: Planejamento e métodos. Bookman editora, 2015. 